\title{
Article \\ Quantification of Total Phenols and Antioxidants in Coffee Samples of Different Origins and Evaluation of the Effect of Degree of Roasting on Their Levels
}

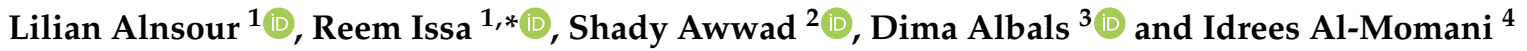 \\ 1 Department of Pharmaceutical Sciences, Pharmacological and Diagnostic Research Center (PDRC), \\ Faculty of Pharmacy, Al-Ahliyya Amman University, Amman 19328, Jordan; l.alnsour@ammanu.edu.jo \\ 2 Department of Pharmaceutical Chemistry \& Pharmacognosy, Applied Science Private University, \\ Amman 11931, Jordan; sh_awwad@asu.edu.jo \\ 3 Department of Medicinal Chemistry and Pharmacognosy, Faculty of Pharmacy, Yarmouk University, \\ Irbid 21163, Jordan; dimabals@yu.edu.jo \\ 4 Department of Chemistry, Faculty of Science, Yarmouk University, Irbid 21163, Jordan; imomani@yu.edu.jo \\ * Correspondence: r.issa@ammanu.edu.jo
}

check for

updates

Citation: Alnsour, L.; Issa, R.;

Awwad, S.; Albals, D.; Al-Momani, I. Quantification of Total Phenols and Antioxidants in Coffee Samples of Different Origins and Evaluation of the Effect of Degree of Roasting on Their Levels. Molecules 2022, 27, 1591. https://doi.org/10.3390/

molecules27051591

Academic Editors: Francesco

Cacciola and George Grant

Received: 31 December 2021

Accepted: 23 February 2022

Published: 28 February 2022

Publisher's Note: MDPI stays neutral with regard to jurisdictional claims in published maps and institutional affiliations.

Copyright: (C) 2022 by the authors. Licensee MDPI, Basel, Switzerland. This article is an open access article distributed under the terms and conditions of the Creative Commons Attribution (CC BY) license (https:// creativecommons.org/licenses/by/ $4.0 /)$.

\begin{abstract}
Phenolic and antioxidant compounds have received considerable attention due to their beneficial effects on human health. The aim of this study is to determine the content of total phenols and antioxidants in fifty-two coffee samples of different origins, purchased from the Jordanian local market, and investigate the effect of the degree of roasting on the levels of these compounds. The coffee samples were extracted using the hot water extraction method, while Folin-Ciocalteu (FC) and 1,1-diphenyl-2-picrylhydrazyl (DPPH) assay methods were used to analyze these compounds. The results showed that the highest content of total phenol $(16.55 \mathrm{mg} / \mathrm{g}$ equivalent to GAE) was found in the medium roasted coffee, and the highest content of antioxidants ( $1.07 \mathrm{mg} / \mathrm{g}$ equivalent to TEAC) content was found in the green coffee. Only light and medium roasted coffee showed a significant correlation $\left(p<0.05, \mathrm{R}^{2}>0.95\right)$ between the average of total phenolic and antioxidant content. A negative correlation between the antioxidant content and the degree of roasting $\left(p<0.05, \mathrm{R}^{2}>0.95\right)$ were shown, while it did not correlate with phenolic contents. Previously, a positive correlation between antioxidant and chlorogenic acids content was observed, with no correlation between the origin of coffee samples nor heavy metal content, which was previously determined for the same coffee samples. These findings suggest that the antioxidant content for coffee extracts is largely determined by its chlorogenic acid content, rather than the coffee origin or total phenolic and heavy metals content.
\end{abstract}

Keywords: coffee; phenols; antioxidant; TEAC; roasting; GAE

\section{Introduction}

Coffee is one of the most popular beverages in the world. It was introduced to the New World in the mid-17th century, although its history dates to the 15th century when coffee plants were supposedly cultivated in Southern Arabia and taken originally from Ethiopia. It was not until the 1950s that instant coffee was produced. Nowadays, Brazil is the top coffee-producing country in the world, followed by Vietnam and Colombia [1].

There are over 120 species of Coffea plant, with Coffea arabica and Coffea canephora (also known as "Robusta") being the most popular commercially. The former contributes to $70 \%$ of the world's coffee consumption. The latter contains more caffeine and lower lipid content, which is why it tastes more bitter [2]. It is also cheaper to produce compared with Coffea arabica [3]. Green coffee beans are the seeds from the coffee tree fruits. The same species of coffee can be cultivated differently to produce a wide variety of coffee beans having different flavors and aromas, depending on the soil, climate, and altitude of their growing areas, which means that coffee is affected by its geographical origin [4]. 
Roasting is also an important determinant of taste and aroma in brewed coffee. Green coffee beans are heated at $200-240^{\circ}$ for $10-15 \mathrm{~min}$, depending on the degree of roasting required. This may considerably alter their chemical composition; lowering the sugars, water, and chlorogenic acids while forming new compounds, such as melanoidins due to the Maillard reaction [5]. In a study by Mayer and others [6], it was shown that the concentration of certain compounds in roasted coffee beans was greatly affected by the degree of roast. For example, Colombian and Kenyan coffees have increasing amounts of phenolic compounds, such as guaiacol, with an increased roasting degree.

The quality of coffee can be affected by levels of chemical fertilizers and pesticides used in soil, which contribute to heavy metal contamination. The preparation method and degree of roasting also affect its final heavy metal composition. Albals et al. [7] determined the heavy metal content in different green and roasted coffee samples consumed in Jordan, taken from five origins: Brazil, Ethiopia, Kenya, Colombia, and India. According to the results, there was a significant difference in the levels of $\mathrm{Zn}, \mathrm{Cr}$, and $\mathrm{Co}$ in green and roasted coffee beans. All levels were below the tolerable upper limit of daily intake (TULD) of metals determined by the World Health Organization (WHO) and thus were safe for consumption.

Coffee is known to be an essential source of antioxidants due to the presence of alkaloids, flavonoids, and phenolic compounds. Consumption of coffee is therefore attributed to improving health [4]. Moreover, it is the main antioxidant found in the diets of Americans, Japanese, Danish, and Brazilians [8].

Phenolic compounds are widely abundant in fruits, vegetables, dry legumes, chocolate, and beverages like coffee, tea, and cocoa [9]. Polyphenols have been shown to have antioxidant effects, which are beneficial to the heart and can protect against oxidative stress that is directly correlated with degenerative diseases, diabetes mellitus, and cancer [10]. Other evidence suggests their anti-inflammatory, antiviral, and antibacterial activity [11]. For instance, green coffee beans have been reported to contain chlorogenic and caffeic acids as the main phenols. These compounds possess antimutagenic and antioxidative effects [8]. Other studies suggest its role in neurodegenerative diseases, such as ischemic strokes and lowering blood pressure in rats [12].

A study by Masek et al. [8] on five different Ethiopian coffee brands has demonstrated a significant total phenolic content and antioxidant activities, which showed that Ethiopian coffee might be used in preventing and curing several degenerative diseases. Another study by Sentkowska et al. [5] was carried out to determine the antioxidant capacity of different green coffee extracts. It has been reported that Robusta green coffee from Laos had the highest antioxidant capacity due to the high concentration of chlorogenic acids. Duarte et al. [13] concluded that roasting is inversely proportional to the polyphenol and antioxidant activity, where light brewed coffee had the highest antioxidant capacity, while dark roasted coffee had the lowest.

While many studies were conducted in Jordan to study the total phenolic content and antioxidant capacity of various plant species [14], only a few of them were carried out on coffee. A previous study by Kandah et al. [14] analyzed total phenolic content and antioxidant activity using methyl linoleate (MeLo) assay for nine samples of green and roasted coffee beans obtained from the Jordanian market. It demonstrated that extraction time, temperature, and particle size were important variables that affected total phenolic content. Another study compared the antioxidant activity of roasted barley and roasted dates with that of two different roasted coffee samples and green coffee samples (Saudi and Colombian origins) using ABTS and DPPH assays. Results indicated that the highest antioxidant activity was observed for Saudi roasted coffee, followed by Colombian roasted coffee, roasted barley, Colombian green coffee, and roasted dates [15].

To the best of our knowledge, this is the first extensive study conducted in Jordan on 52 different coffee samples with the aim to evaluate the effect of roasting and geographical origin on the antioxidant and total phenolic content of coffee beans available in the Jordanian market, using 1,1-diphenyl-2- picrylhydrazyl (DPPH) and Folin-Ciocalteu (FC) assays, 
respectively, for this purpose. All samples were prepared by water extraction similar to the way normally used when preparing the beverage, to investigate the individual's intake of antioxidant phenols by consuming coffee brew. The secondary aim was to find a correlation (if any) between the antioxidant activity and total phenolic content of different types of coffee beans, with their caffeine, chlorogenic acids, and heavy metal content, the latter that were previously determined by our research group (Albals et al.) (Awwad et al.) [7,16].

\section{Results}

\subsection{Total Polyphenols Content}

The average total phenolic content, expressed as milligrams of gallic acid equivalents per gram of dry coffee extract (GAE mg/g), was determined for 52 Coffea arabica samples of different origins and roasting degrees, as shown in Supplementary Table S1. These samples have shown variations in total phenolic content ranging from $14.92 \mathrm{mg} / \mathrm{g}$ to $16.55 \mathrm{mg} / \mathrm{g}$ (Figure 1), reported for dark roasted coffee and medium roasted coffee, respectively. Except for green coffee beans, the variety from Kenya showed to have the lowest total phenolic content, while the variety from Colombia showed to have the highest total phenolic content (Table 1). For green coffee beans, the variety from Kenya showed to have the highest total phenolic content, which was decreasing in its content by the roasting process in varying amounts. While the variety from Colombia showed the opposite behavior upon roasting, as its content of phenols tends to increase by increasing the roasting degree.

Table 1. Comparison of different roasting degrees for coffee samples from different geographical origins according to their total phenolic and antioxidant activity (GAE mg/g and TEAC $\mathrm{mg} / \mathrm{g}$, respectively).

\begin{tabular}{|c|c|c|}
\hline Geographical Origin & $\begin{array}{c}\text { GAE } \\
\mathrm{mg} / \mathrm{g} \pm \mathrm{SD}\end{array}$ & $\begin{array}{c}\text { TEAC } \\
\mathrm{mg} / \mathrm{g} \pm \mathrm{SD}\end{array}$ \\
\hline \multicolumn{3}{|c|}{ Green Coffee } \\
\hline Kenya & $17.25 \pm 0.14$ & $1.29 \pm 0.04$ \\
\hline Ethiopia & $14.55 \pm 0.10$ & $1.13 \pm 0.11$ \\
\hline Brazil & $13.82 \pm 0.13$ & $0.97 \pm 0.14$ \\
\hline Colombia & $16.72 \pm 0.05$ & $0.88 \pm 0.08$ \\
\hline Average & $15.59 \pm 1.65$ & $1.07 \pm 0.18$ \\
\hline \multicolumn{3}{|c|}{ Light Coffee } \\
\hline Kenya & $9.84 \pm 0.02$ & $0.84 \pm 0.05$ \\
\hline Ethiopia & $16.35 \pm 0.05$ & $0.96 \pm 0.03$ \\
\hline Brazil & $17.11 \pm 0.05$ & $0.94 \pm 0.07$ \\
\hline Colombia & $19.05 \pm 0.13$ & $1.07 \pm 0.14$ \\
\hline Average & $15.59 \pm 4.00$ * & $0.95 \pm 0.09 *$ \\
\hline \multicolumn{3}{|c|}{ Medium Coffee } \\
\hline Kenya & $12.31 \pm 0.02$ & $0.65 \pm 0.12$ \\
\hline Ethiopia & $14.93 \pm 0.14$ & $1.13 \pm 0.01$ \\
\hline Brazil & $14.66 \pm 0.05$ & $1.07 \pm 0.07$ \\
\hline Colombia & $24.28 \pm 0.11$ & $0.08 \pm 0.02$ \\
\hline Average * & $16.55 \pm 5.29 * *$ & $0.73 \pm 0.48^{* *}$ \\
\hline \multicolumn{3}{|c|}{ Dark Coffee } \\
\hline Kenya & $9.44 \pm 0.11$ & $0.60 \pm 0.10$ \\
\hline Ethiopia & $12.24 \pm 0.14$ & $0.43 \pm 0.10$ \\
\hline Brazil & $16.60 \pm 0.14$ & $0.47 \pm 0.17$ \\
\hline Colombia & $21.41 \pm 0.20$ & $0.46 \pm 0.15$ \\
\hline Average & $14.92 \pm 5.23$ & $0.49 \pm 0.07$ \\
\hline
\end{tabular}

$*{ }^{* *}$ Results are statistically significant with $p$-value $<0.05, \mathrm{R}^{2}>0.95$. 


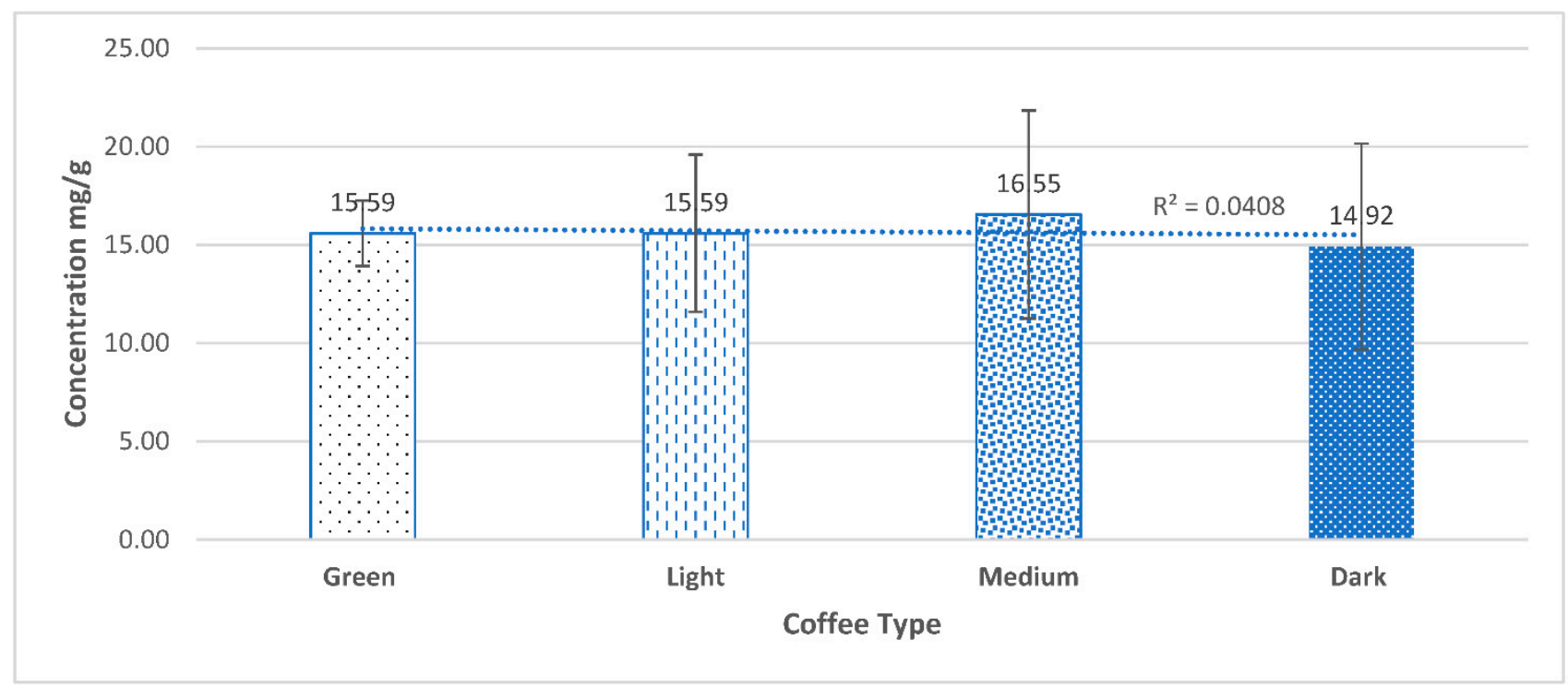

Figure 1. The average total phenolic content (mg/g GAE) for each roasting degree with (different geographical origin). No correlation was found between roasting degree and total phenolic content. $\left(R^{2}=0.041\right)$. Results are statistically insignificant with a $p$-value $>0.05$.

\subsection{Antioxidant Activity of Coffee Samples}

The average antioxidant activity - expressed as milligrams of Trolox equivalents antioxidant capacity per gram dry coffee extract (TEAC mg/g) - was determined for 52 Coffea arabica samples of different origins and roasting degrees, as shown in Supplementary Table $\mathrm{S} 1$. The values ranged from $0.49 \mathrm{mg} / \mathrm{g}$ to $1.07 \mathrm{mg} / \mathrm{g}$, reported for dark roasted coffee and green coffee, respectively (Figure 2). The antioxidant activity was correlated with the roasting degree of coffee beans. Although the content of phenols showed a consistent pattern in terms of the geographical origin of coffee beans, no correlation was found for the antioxidant activity with the origin (Table 1). Only light and medium roasted coffee showed a significant correlation between the average total phenolic content and the average antioxidant content.

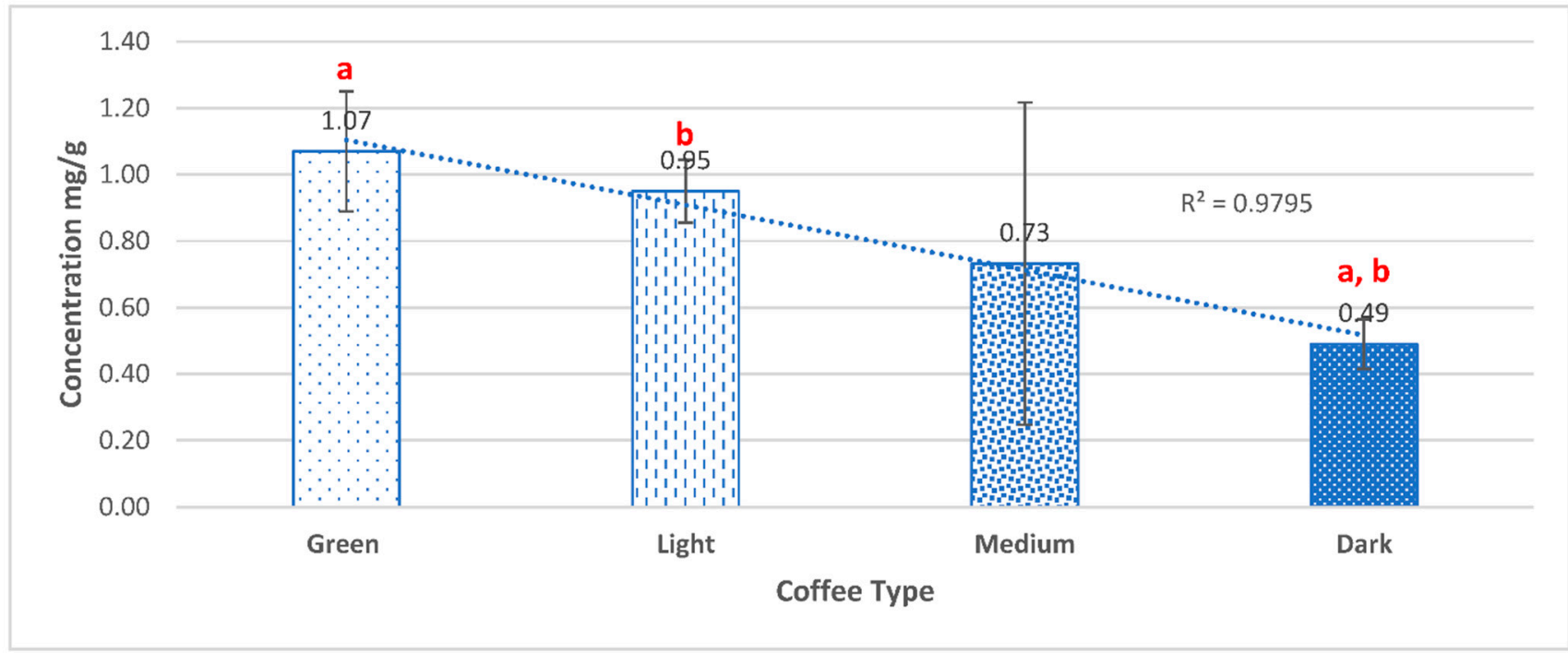

Figure 2. The average antioxidant activity (mg/g TEAC) for each roasting degree (different geographical origin) A negative correlation was found between roasting degree and TEAC $\mathrm{mg} / \mathrm{g}\left(\mathrm{R}^{2}=0.98\right)$. Bars labeled ${ }^{\mathrm{a}, \mathrm{b}}$ are statistically significant with a $p$-value $<0.05$. 
2.3. Comparison of the Content of Total Phenol, Antioxidant, and Heavy Metal in Selected Coffee Samples

Figures 3 and 4 show a comparison of coffee samples of different geographical origins (regardless of their roasting degree) and roasting degrees (regardless of their origin) in terms of average GAE in $\mathrm{mg} / \mathrm{g}$, average TEAC in $\mathrm{mg} / \mathrm{g}$, and average $\mathrm{Zn}, \mathrm{Pb}$, and $\mathrm{Cu}$ contents in $\mu \mathrm{g} / \mathrm{g}$ (Data for heavy metal content was taken from Albals et al. [7]).



Figure 3. Comparison of coffee samples from different origins (regardless of their roasting degree) in terms of average GAE in $\mathrm{mg} / \mathrm{g}$, average TEAC in $\mathrm{mg} / \mathrm{g}$, and average $\mathrm{Zn}, \mathrm{Pb}$, and $\mathrm{Cu}$ contents in $\mu \mathrm{g} / \mathrm{g}$. (Data for heavy metal content taken from Albals et al. [7]). Bars labeled ${ }^{a, b, c}$ are statistically significant with a $p$-value $<0.05$.

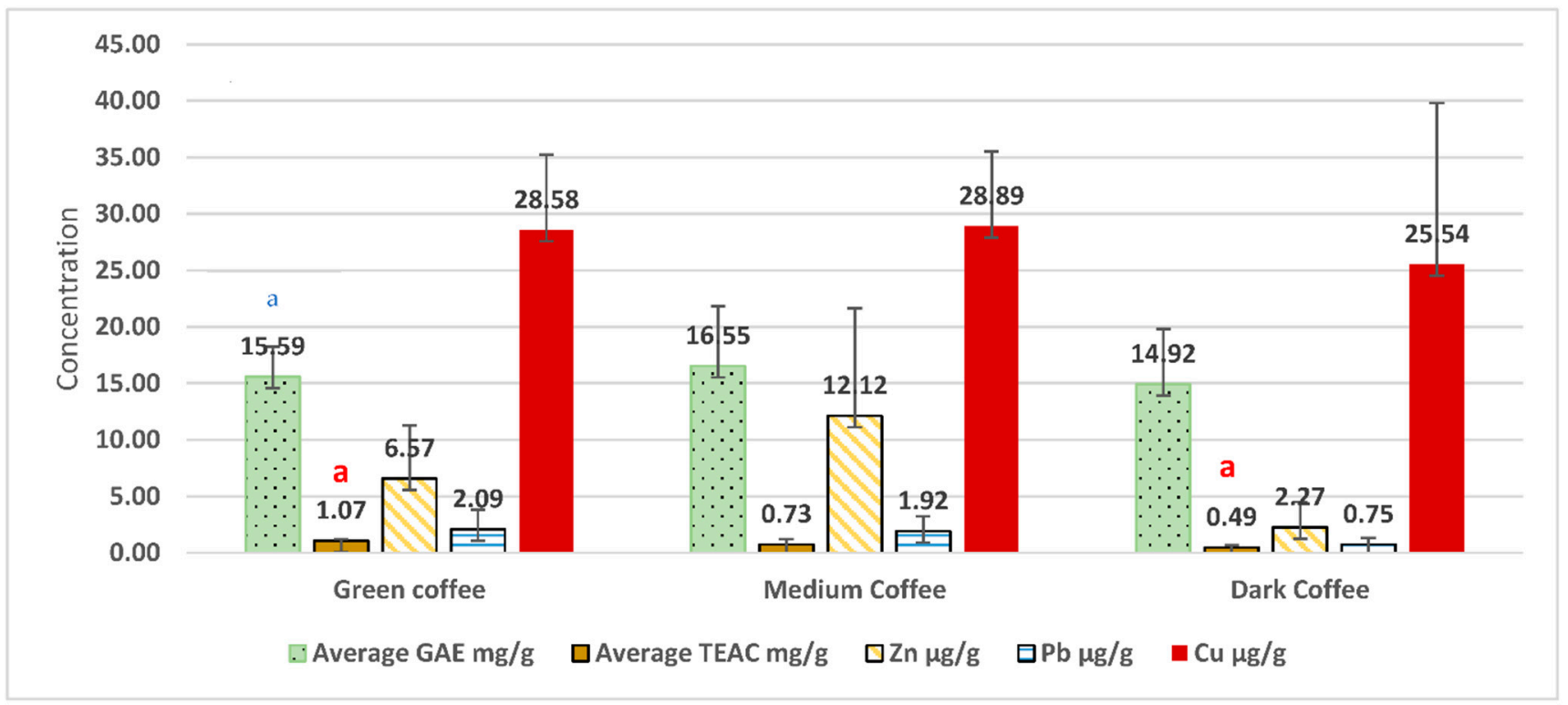

Figure 4. Comparison of coffee samples of three different roasting degrees (regardless of their origin) in terms of average GAE in $\mathrm{mg} / \mathrm{g}$, average TEAC in $\mathrm{mg} / \mathrm{g}$, and average $\mathrm{Zn}, \mathrm{Pb}$, and Cu contents in $\mu \mathrm{g} / \mathrm{g}$. (Data for heavy metal content was taken from Albals et al. [7]). Bars labeled a are statistically significant with a $p$-value $<0.05$. 


\section{Discussion}

The roasting degree and geographical origins are key factors affecting both the total phenolic content and the antioxidant activity of the coffee beans [17]. Therefore, this study focused on evaluating the effect of these variables on the antioxidant and phenolic compound contents in coffee samples available in the Jordanian market. In addition, this study aimed to explore the individual intake of phenols and antioxidants from coffee beverages commonly used among Jordanian citizens, known as "Turkish coffee". Since antioxidant compounds provide health benefits, coffee as a beverage is claimed to be of great interest for individuals who are trying to increase their intake of these nutrients [18]. Consequently, such findings should reveal the actual individual intake of these nutrients that would influence their health status.

The findings of the current study are in good agreement with the previous study by Król et al. [17], which showed that the highest content of total polyphenolic compounds was determined in coffee samples roasted in light and medium roasting conditions, and was better for preserving these nutrients.

A previous study by Bobková et al. [19] showed a correlation between phenolic content and antioxidant activity. On the contrary, the current findings showed that no correlation was found between phenolic content, antioxidant activity, or geographical origin. Medium roasted beans appeared to contain higher average polyphenols than the green beans, where the variety from Colombia showed to have the highest phenolic content among the roasted samples (regardless of the roasting degree), but with varied antioxidant activity.

As expected, statistical analyses of these data revealed a significant influence $(p<0.05$. $R^{2}=0.98$ ) of the roasting degree on the antioxidant activity, which was decreasing with the increase in the degree of roasting. Cho et al. [20] studied the influence of roasting conditions on the antioxidant characteristics of Colombian coffee of the species Coffea arabica beans. They found that light-roasted coffee beans have the highest antioxidant activity, and an approximately $40-80 \%$ loss of antioxidant activity was observed after further roasting. In addition, they also detected significantly higher antioxidant activity as compared to unroasted beans, suggesting the formation of Maillard reaction products and the release of bound polyphenols from plant cells. These data suggested the formation of new phenolic compounds, other than the ones detected in the variety from Colombia, but with no effect on their antioxidant content.

Green coffee beans showed the highest content of phenols in the species from Kenya. The latter also showed the highest antioxidant activity compared to the other studied samples. In fact, different varieties of coffee samples showed a low and narrow range of phenolic content compared to the previous studies [21,22]. This could be explained by the fact that phenolic compounds are often more soluble in alcohol extracts compared to water, which was used in this study.

A previous study by Górnaś et al. [23], which investigated the contribution of phenolic acids isolated from green and roasted boiled-type coffee brews to total coffee antioxidant capacity, showed that the antioxidant effect can be poorly correlated with polyphenols' concentration when the DPPH assay method is used, which agrees with the findings of this study. The antioxidant activity changes in extracts from green, light, medium, and dark roasted coffee are negatively influenced by the intensity of the heating process and seem to be much more dependent on the roasting degree than on the geographical origin of coffee beans. Similarly, Bilge [24] conducted a study investigating the effects of geographical origin, roasting degree, particle size, and brewing method on the physicochemical and spectral properties of Arabica coffee. It showed that roasting degree and brewing method-compared with other parameters-were the most discriminating factors based on UV and fluorescence spectra of coffee brew samples, respectively. On the contrary, Muzykiewicz-Szymańska et al. [25] studied the effect of brewing process parameters on antioxidant activity in infusions of roasted and unroasted Arabica coffee beans originating from different countries. They concluded that the phenolic compound content in infusions 
prepared using different techniques depended on the roasting process, the bean's origin, as well as the brewing technique.

Based on the results from the study by Albals, et al. [7] which investigated the heavy metals contents for the same coffee samples that were analyzed in this study, the data showed that there was no clear correlation between the content of phenols, antioxidant compounds, and heavy metals content. Therefore, these findings suggest that roasting degree would affect the antioxidant activity, regardless of the geographical origin or heavy metal content. Nevertheless, the geographical origin had shown an impact only on the total phenolic content, with no effect on any of the other measured variables.

Results from a study - that was recently published by our research group-which determined the chlorogenic acids (CGAs) and caffeine content for the same coffee samples, have shown that the highest content of caffeine was found in the medium roasted coffee $(203.63 \mathrm{mg} / \mathrm{L})$, and the highest content of CGA was found in the green coffee $(543.23 \mathrm{mg} / \mathrm{L})$. The results demonstrated a negative correlation between the CGA levels with the degree of roasting, while it showed a positive correlation between the caffeine levels with the degree of roasting before it starts to decline in the dark roasted coffee [16].

Comparing these results with the current study, it can be concluded that the coffee samples with the highest CGA content have also shown the highest antioxidant activity, which suggests that CGAs alone rather than total phenolic content contribute to the antioxidant activity of coffee. Furthermore, the geographical origin did not seem to affect the content of either CGA or caffeine, as it did not affect the total phenolic content and antioxidant activity determined in this study [16].

This study showed the need to perform more research using different assays to investigate the relationship between the antioxidant activity with the total phenolic content.

\section{Methods and Materials}

\subsection{Chemicals and Standards}

For the determination of the total phenolic content, the FC reagent (2N, Sigma-Aldrich, Schaffhausen, Switzerland), gallic acid (GA) (99\% purity, Sigma), and anhydrous sodium carbonate (99\% purity, Sigma) were used. For the determination of the antioxidant activity, DPPH (Aldrich, Darmstadt, Germany), Trolox (Sigma-Aldrich, Switzerland), and methanol (for HPLC > 99.9\%, Sigma-Aldrich, St. Quentin Fallavier, France) were employed.

For this study, fifty-two samples of ground coffee beans (Coffea arabica), including green (11 samples), light-roasted (14 samples), medium roasted (11 samples), and dark roasted (16 samples), from different origins were purchased from different grocery stores across Jordan (Amman, Irbid) in 2019 and stored in the freezer.

\subsection{Sample Preparation and Extraction}

The coffee samples were freshly extracted according to the extraction procedure described by Perez Hernandez et al. [26], with few modifications. The coffee samples were extracted with hot water at $75-80{ }^{\circ} \mathrm{C}$ at a $1 / 100$ coffee-to-solvent ratio, where $1 \mathrm{~g}$ of coffee was extracted with $100 \mathrm{~mL}$ of water. Then, ultrasonication was performed for $5 \mathrm{~min}$ to homogenize the solutions using an ultrasonic bath (OVAN). Afterwards, the samples were centrifuged for $15 \mathrm{~min}$ at $7900 \times g$ using an (MPW-260R) centrifuge system. Next, all coffee solutions were filtered with Whatman No. 2 filter paper. Finally, the coffee extracts were stored at a temperature of $-20{ }^{\circ} \mathrm{C}$ until the day of analysis (May-August 2020).

\subsection{Determination of Total Phenolic Content}

Total phenolic content was measured using the FC method by Singleton et al. [27]. A stock solution of $10 \mathrm{mg} / \mathrm{mL}$ of extract in water was prepared for each sample. Three different concentrations were made for each extract by serial dilution; $5 \mathrm{mg} / \mathrm{mL}, 2.5 \mathrm{mg} / \mathrm{mL}$ and $1.25 \mathrm{mg} / \mathrm{mL}$. An aliquot of $80 \mu \mathrm{L}$ of each aqueous solution of extract was added to $400 \mu \mathrm{L}$ of dilute Folin-Ciocalteu (1:10) reagent in a test tube. Then $320 \mu \mathrm{L}$ of $7.5 \%$ sodium carbonate solution was added. The solution was covered with aluminum foil and incubated 
in a water bath at $45^{\circ} \mathrm{C}$ for $30 \mathrm{~min}$. The absorbance was recorded at $765 \mathrm{~nm}$ using a UVVis spectrophotometer against the blank solution (water only). The measurement was compared to a calibration curve prepared with GA solution at a concentration range from $(0-0.12 \mathrm{mg} / \mathrm{mL})$, and the total phenolic content was expressed as GAE $\mathrm{mg} / \mathrm{g}$, using the standard curve equation:

$$
y=7.515 x+0.0308, R^{2}=0.9927
$$

where $\mathrm{y}$ is the absorbance at $765 \mathrm{~nm}$ and $\mathrm{x}$ is the total phenolic content in the different extracts expressed in $\mathrm{mg} / \mathrm{mL}$.

\subsection{Determination of Antioxidant Capacity}

Aliquots of $2 \mathrm{~mL}$ of each plant extract were dried in the oven overnight at a temperature of $50{ }^{\circ} \mathrm{C}$ to dry all the water. An amount of $2 \mathrm{~mL}$ of methanol was added to each dried sample and vortexed for 3 min to allow a homogenous stock solution of concentration $10 \mathrm{mg} / \mathrm{mL}$. Three different concentrations were made for each extract by serial dilution; $5 \mathrm{mg} / \mathrm{mL}, 2.5 \mathrm{mg} / \mathrm{mL}$ and $1.25 \mathrm{mg} / \mathrm{mL}$. A solution of $0.1 \mathrm{mM}$ DPPH in methanol was prepared fresh for the assay. Then, $300 \mu \mathrm{L}$ of the sample was added to $100 \mu \mathrm{L}$ of DPPH solution, shaken, and incubated for $30 \mathrm{~min}$ in the dark at room temperature. Absorbance was monitored at $517 \mathrm{~nm}$ using a UV-Vis spectrophotometer. The reaction mixture containing control and reference standard ( $300 \mu \mathrm{L}$ methanol and $100 \mu \mathrm{L}$ DPPH solution) were also measured. The measurement was compared to a calibration curve prepared with Trolox solution at a concentration range from $(0-50 \mu \mathrm{M})$. The antioxidant capacity was expressed as TEAC $\mathrm{mg} / \mathrm{g}$, using the standard curve equation:

$$
y=-0.024 x+1.36, R^{2}=0.992
$$

where $\mathrm{y}$ is the DPPH absorbance at $517 \mathrm{~nm}$ and $\mathrm{x}$ is the Trolox concentration in the different extracts expressed in $\mu \mathrm{M}$, which is then expressed as mg TEAC/g of dry extract.

\subsection{Statistical Analysis}

All measurements were performed in triplicates and results were reported as mean \pm standard deviation. The results were analyzed statistically using one-way analysis of variance (ANOVA) on Microsoft Excel with its data analysis add-ins. The mean values of GAE mg/g were compared with TEAC $\mathrm{mg} / \mathrm{g}$ to assess the existence of statistical significance using measurements of $p$-value and squared correlation coefficients $\left(\mathrm{R}^{2}\right)$. The level of significance was set to 0.05 and 0.95 , respectively.

Supplementary Materials: The following supporting information can be downloaded online, Table S1: The distribution of Coffea arabica samples (52) obtained from the Jordanian market according to their origin and roasting degree. Roasting temperatures for light roasted $=155-165^{\circ} \mathrm{C}$, for medium roasted $=175-185^{\circ} \mathrm{C}$, and for dark roasted $=205-215^{\circ} \mathrm{C}$. Table S2: The Average concentration $(\mathrm{mg} / \mathrm{g})$, $\mathrm{SD}, \mathrm{SE}$, Min, Max, and confidence interval for GAE in coffee beans obtained from the Jordanian market. Table S3: The Average concentration (mg/g), SD, SE, Min, Max, and confidence interval for TEAC in coffee beans obtained from the Jordanian market.

Author Contributions: L.A.: samples analysis, and writing the first manuscript. R.I.: corresponding author, methodology design, and conceptualization. S.A.: Experimental analysis, writing-review and editing. D.A.: samples collection and resources. I.A.-M.: Data Analysis, editing the manuscript. All authors have read and agreed to the published version of the manuscript.

Funding: This research received no external funding.

Institutional Review Board Statement: This study did not require ethical approval.

Informed Consent Statement: Not applicable.

Data Availability Statement: Not applicable. 
Acknowledgments: The authors are grateful to the Pharmacological and Diagnostic Research Center (PDRC), Faculty of Pharmacy, and Al-Ahliyya Amman University, for the full support for this research project.

Conflicts of Interest: The authors report no conflicts of interest in this work.

Sample Availability: Samples of the standard compounds are available from the authors.

\section{References}

1. Myhrvold, N. Coffee. Encyclopedia Britannica. Available online: https://www.britannica.com/topic/coffee (accessed on 19 February 2022).

2. Urgert, R.; Katan, M.B. The Cholesterol-Raising Factor from Coffee Beans. J. R. Soc. Med. 1996, 89, 618-623. [CrossRef] [PubMed]

3. Miyanari, W. Aloha Coffee Island; Savant Books \& Publications: Singapore, 2008; ISBN 978-0-615-18348-0.

4. Tewabe, B. Determination of Caffeine Content and Antioxidant Activity of Coffee. Am. J. Appl. Chem. 2015, 3, 69. [CrossRef]

5. Sentkowska, A. Comparative Studies on the Antioxidant Properties of Different Green Coffee Extracts. MOJ Food Process. Technol. 2016, 3, 71. [CrossRef]

6. Mayer, F.; Czerny, M.; Grosch, W. Influence of Provenance and Roast Degree on the Composition of Potent Odorants in Arabica Coffees. Eur. Food Res. Technol. 1999, 209, 242-250. [CrossRef]

7. Albals, D.; Al-Momani, I.F.; Issa, R.; Yehya, A. Multi-Element Determination of Essential and Toxic Metals in Green and Roasted Coffee Beans: A Comparative Study among Different Origins Using ICP-MS. Sci. Prog. 2021, 104, 1-17. [CrossRef]

8. Masek, A.; Latos-Brozio, M.; Kałużna-Czaplińska, J.; Rosiak, A.; Chrzescijanska, E. Antioxidant Properties of Green Coffee Extract. Forests 2020, 11, 557. [CrossRef]

9. $\quad$ Engida, A.M.; Faika, S.; Nguyen-Thi, B.T.; Ju, Y.-H. Analysis of Major Antioxidants from Extracts of Myrmecodia Pendans by UV/Visible Spectrophotometer, Liquid Chromatography/Tandem Mass Spectrometry, and High-Performance Liquid Chromatography/UV Techniques. J. Food Drug Anal. 2015, 23, 303-309. [CrossRef]

10. Scalbert, A.; Johnson, I.T.; Saltmarsh, M. Polyphenols: Antioxidants and Beyond. Am. J. Clin. Nutr. 2005, 81, 215S-217S. [CrossRef]

11. Farah, A.; Donangelo, C. Phenolic Compounds in Coffee. Braz. J. Plant Physiol. 2006, 18, 23-36. [CrossRef]

12. Jeszka-Skowron, M.; Stanisz, E.; Peña, M.P.D. Relationship between Antioxidant Capacity, Chlorogenic Acids and Elemental Composition of Green Coffee. LWT 2016, 73, 243-250. [CrossRef]

13. Duarte, S.; Abreu, C.; Menezes, H.; Santos, M.; Gouvea, C. Effect of Processing and Roasting on the Antioxidant Activity of Coffee Brews. Food Sci. Technol. 2005, 25, 387-393. [CrossRef]

14. Kandah, M.I.; Ereifej, K.I.; Al-Azzeh, M.A. Characterization and Quantification of Phenolic Compounds in Coffee Beans and Waste. Int. J. Adv. Sci. Eng. Technol. 2019, 7, 33-41.

15. Tarawneh, M.; Al-Jaafreh, A.; Dalaeen, H.; Qaralleh, H.; Alqaraleh, M.; Khataibeh, M. Roasted Date and Barley Beans as an Alternative's Coffee Drink: Micronutrient and Caffeine Composition, Antibacterial and Antioxidant Activities. Syst. Rev. Pharm. 2021, 12, 1079-1083. [CrossRef]

16. Awwad, S.; Issa, R.; Alnsour, L.; Albals, D.; Al-Momani, I. Quantification of Caffeine and Chlorogenic Acid in Green and Roasted Coffee Samples Using HPLC-DAD and Evaluation of the Effect of Degree of Roasting on Their Levels. Molecules 2021, $26,7502$. [CrossRef] [PubMed]

17. Król, K.; Gantner, M.; Tatarak, A.; Hallmann, E. The Content of Polyphenols in Coffee Beans as Roasting, Origin and Storage Effect. Eur. Food Res. Technol. 2020, 246, 33-39. [CrossRef]

18. Castaldo, L.; Narváez, A.; Izzo, L.; Graziani, G.; Ritieni, A. In Vitro Bioaccessibility and Antioxidant Activity of Coffee Silverskin Polyphenolic Extract and Characterization of Bioactive Compounds Using UHPLC-Q-Orbitrap HRMS. Molecules 2020, $25,2132$. [CrossRef] [PubMed]

19. Bobková, A.; Hudáček, M.; Jakabová, S.; Belej, L’.; Capcarová, M.; Čurlej, J.; Bobko, M.; Árvay, J.; Jakab, I.; Čapla, J.; et al. The Effect of Roasting on the Total Polyphenols and Antioxidant Activity of Coffee. J. Environ. Sci. Health B 2020, 55, 495-500. [CrossRef]

20. Cho, A.R.; Park, K.W.; Kim, K.M.; Kim, S.Y.; Han, J. Influence of Roasting Conditions on the Antioxidant Characteristics of Colombian Coffee (Coffea arabica L.) Beans. J. Food Biochem. 2014, 38, 271-280. [CrossRef]

21. Pushpa, S. Murthy Recovery of Phenolic Antioxidants and Functional Compounds from Coffee Industry By-Products. Food Bioprocess Technol. 2012, 5, 897-903. [CrossRef]

22. Mussatto, S.I.; Ballesteros, L.F.; Martins, S.; Teixeira, J.A.C. Extraction of Antioxidant Phenolic Compounds from Spent Coffee Grounds. Sep. Purif. Technol. 2011, 83, 173-179. [CrossRef]

23. Górnaś, P.; Dwiecki, K.; Siger, A.; Tomaszewska-Gras, J.; Michalak, M.; Polewski, K. Contribution of Phenolic Acids Isolated from Green and Roasted Boiled-Type Coffee Brews to Total Coffee Antioxidant Capacity. Eur. Food Res. Technol. 2016, 242, 641-653. [CrossRef]

24. Bilge, G. Investigating the Effects of Geographical Origin, Roasting Degree, Particle Size and Brewing Method on the Physicochemical and Spectral Properties of Arabica Coffee by PCA Analysis. J. Food Sci. Technol. 2020, 57, 3345-3354. [CrossRef] [PubMed] 
25. Muzykiewicz-Szymańska, A.; Nowak, A.; Wira, D.; Klimowicz, A. The Effect of Brewing Process Parameters on Antioxidant Activity and Caffeine Content in Infusions of Roasted and Unroasted Arabica Coffee Beans Originated from Different Countries. Molecules 2021, 26, 3681. [CrossRef] [PubMed]

26. Pérez-Hernández, L.; Chavez-Quiroz, K.; Medina-Juárez, L.A.; Gámez-Meza, N. Phenolic Characterization, Melanoidins, and Antioxidant Activity of Some Commercial Coffees from Coffea arabica and Coffea canephora. J. Mex. Chem. Soc. 2012, 56, 430-435.

27. Singleton, V.L.; Orthofer, R.; Lamuela-Raventós, R.M. Analysis of Total Phenols and Other Oxidation Substrates and Antioxidants by Means of Folin-Ciocalteu Reagent. Methods Enzymol. 1999, 299, 152-178. 